\title{
A RELATIVIZAÇÃO DO PRINCÍPIO DA PRESUNÇÃO DE INOCÊNCIA A PARTIR DA MUTAÇÃO CONSTITUCIONAL NO HABEAS CORPUS N. 126.292
}

\section{THE RELATIVIZATION OF THE PRINCIPLE OF PRESUMPTION OF INNOCENCE FROM THE CONSTITUTIONAL MUTATION IN HABEAS CORPUS N. 126.292}

\author{
Almir Megali Neto \\ Bacharel em Direito pela Universidade Federal de Minas Gerais e Mestrando em Direito pelo PPGD \\ da Universidade Federal de Minas Gerais - UFMG.
}

Recebimento: $15 / 03 / 2018$

Aprovação: 22/06/2018

\section{Como citar este artigo:}

A relativização do princípio da presunção de inocência a partir da mutação constitucional no habenas corpus $n$. 126.292. NETO, Almir Negali. In: Revice - Revista de Ciências do Estado, Belo Horizonte, v.3, n.2, p. 174-195, jun./dez.2018. ISSN 2525-8036.

RESUMO: Este trabalho tem como objeto de estudo a decisão proferida pelo Supremo Tribunal Federal (STF) nos autos do habeas corpus n. 126.292 (HC n. 126.292) que relativizou o princípio da presunção de inocência do art. $5^{\circ}$, inciso LVII, da Constituição da República Federativa do Brasil de 1988 (CRFB/88). Aqui, o esforço recairá na tarefa de demonstrar a inadequação dos fundamentos utilizados pelo voto do Ministro (Min.) Luís Roberto Barroso no HC n. 126.292 em duas perspectivas. Em primeiro lugar, sustenta-se a existência de uma inconsistência teórica interna ao voto proferido por Barroso, na medida em que o Ministro se afastou das vertentes teóricas por ele suscitadas em seu próprio voto. Em segundo lugar, será evidenciada a insuficiência da mutação constitucional para lidar com a relação entre Direito e política e com a força normativa dos princípios jurídicos.

PALAVARAS-CHAVE: habeas corpus n. 126.292; mutação constitucional; presunção de inocência; relativização.

ABSTRACT: The purpose of this work is study the decision pronounced by the Brazilian Supreme Court (Supremo Tribunal Federal - STF) in the habeas corpus n. 126.292 (HC n. 126.292), which 
referred to the principle of the presumption of innocence of article 5, LVII, of the Constitution of the Federative Republic of Brazil of 1988 (CRFB/ 88). Here the effort will fall on the task of demonstrating the inadequacy of the foundations used by the vote of the Justice Luís Roberto Barroso in HC n. 126.292 in two perspectives. First, the existence of an internal theoretical inconsistency to Barroso's vote is maintained, as the Justice has departed from the theoretical strands he raised in his own vote. Second, there will be evidence of the insufficiency of the constitutional mutation to deal with the relationship between law and politics and with the normative force of principles.

KEYWORDS: habeas corpus n. 126.292; constitutional mutation; presumption of innocence; relativization.

\section{INTRODUÇÃO}

Às vésperas de completar trinta anos de promulgação, a Constituição brasileira de 1988 daria, para alguns, sinais de insuficiência. Haveria um sentimento de frustração por parte de parcela da sociedade brasileira em relação às promessas não cumpridas da Constituição. A falta de efetividade das normas constitucionais teria criado uma realidade social distinta daquela prevista pela Constituição. Esta seria, portanto, a razão para o fracasso institucional brasileiro. ${ }^{76} \mathrm{Em}$ tal perspectiva, os temas de Direito Constitucional deveriam ser apreendidos de maneira a promover tanto quanto possível a aproximação entre o dever-ser normativo e o ser da realidade social. ${ }^{77}$

Em sua Tese de Titularidade em Direito Constitucional, Cattoni de Oliveira (2017, p. 01), sustenta a necessidade de superação desta "metodologia dualista, entre um enfoque jurídiconormativo (dever-ser) e/ou um enfoque sociopolítico (ser), de abordagem do Direito e do Estado" ainda presente na teoria tradicional da constituição, de modo que efetividade e legitimidade constitucionais sejam adequadamente compreendidas. A mutação constitucional é um dos instrumentais teóricos que, no marco daquilo que Cattoni de Oliveira denomina de teoria tradicional da constituição, pretende lidar com a relação entre normatividade constitucional e realidade dos processos político-sociais.

No julgamento do HC n. 126.292, o STF considerou que o princípio da presunção de inocência do art. $5^{\circ}$, inciso LVII, da CRFB/88, não impediria o cumprimento provisório de pena

\footnotetext{
${ }^{76}$ Nesse sentido, veja-se: Barroso (2018, p. 57-97).

${ }^{77}$ Há, ainda, aqueles para os quais o quadro de frustração em relação à Constituição de 1988 somente poderia ser superado com a convocação de uma Assembleia Nacional Constituinte ou de uma constituinte exclusiva. Para uma visão crítica desta posição veja-se: Cattoni de Oliveira e Gomes (2016).
}

175 NETO, Almir Megali. A relativização do princípio da presunção de inocência a partir da mutação constitucional no habeas corpus n. 126.292 
privativa de liberdade determinada por acórdão penal condenatório preferido por tribunal de segunda instância. Neste julgado, que constitui objeto de estudo do presente trabalho, destaca-se o voto do Min. Luís Roberto Barroso que, com apoio na mutação constitucional, votou pela constitucionalidade do sobredito entendimento.

No entanto, este entendimento não é isento de críticas. Em primeiro lugar, é possível fazer uma crítica interna ao recurso à mutação constitucional realizado por Barroso que, pretendendo se alinhar à sua concepção doutrinária e à concepção de Konrad Hesse sobre a mutação constitucional acabou, ao final, se aproximando mais das concepções de Georg Jellinek, Rudolf Smend e Hsü DauLin. Em segundo lugar, mesmo que o Min. Luís Roberto Barroso tivesse se mantido fiel à concepção doutrinária por ele suscitada em seu voto, pode-se dizer que o recurso à mutação constitucional expressa uma visão incapaz de lidar com a relação existente entre o Direito e política e com o papel normativo desempenhado pelos princípios jurídicos no marco de uma teoria da constituição hermeneuticamente considerada.

Para desenvolver as críticas brevemente expostas acima, o presente trabalho está organizado da seguinte maneira: na seção 2, pretende-se recuperar os elementos constitutivos do caso concreto para, em seguida, proceder a um estudo crítico do manejo da mutação constitucional como fundamento apto a subsidiar a relativização do princípio da presunção de inocência no HC n. 126.292.

Na seção 3, pretende-se relacionar a mutação constitucional suscitada pelo Min. Luís Roberto Barroso em seu voto ao debate doutrinário ocorrido na Alemanha, formulando questionamentos críticos ao manejo do referido instrumental teórico pelo Poder Judiciário. Aqui, será possível vislumbrar que, ao utilizar a mutação constitucional, Barroso se aproximou da doutrina de autores como Jellinek, Smend e Dau-Lin revelando, assim, o potencial autoritário do instituto e do seu próprio. Além disso, demonstrar-se-á, na seção 4, a incapacidade do instrumental teórico da mutação constitucional para lidar com a relação entre Direito e política e com os princípios jurídicos como espécies de norma jurídica que são.

Ao final, concluir-se-á pela inadequação do manejo da mutação constitucional como suposto fundamento apto a admitir a relativização do princípio da presunção de inocência no HC n. 126.292, atentando-se, sempre, para as distinções entre o modus operandi da função jurisdicional e das demais instâncias políticas de poder, a fim de resguardar a normatividade própria dos princípios jurídicos. 


\section{A COMPREENSÃO ACERCA DA MUTAÇÃO CONSTITUCIONAL A PARTIR DO HC N. 126.292}

\section{o CASO EM JUÍzo}

Na origem, o paciente do HC n. 126.292, foi condenado pelo crime de roubo majorado pelo uso de arma de fogo e concurso de pessoas. A defesa, prontamente interpôs apelação e o recurso foi distribuído à $4^{\mathrm{a}}$ Câmara Criminal do Tribunal de Justiça do Estado de São Paulo (TJ/SP) que, negando-lhe provimento, determinou, ainda, o cumprimento imediato de pena privativa de liberdade.

Em virtude disso, a defesa impetrou habeas corpus perante o Superior Tribunal de Justiça (STJ). Liminarmente, foi requerida a suspensão imediata do mandado de prisão expedido pelo órgão fracionário do TJ/SP, uma vez que, no caso, não se faziam presentes os requisitos autorizativos da medida e não tinha havido o trânsito em julgado da sentença penal condenatória.

Ocorre que o Min. Francisco Falcão, Presidente do STJ à época dos fatos, indeferiu o pedido liminar requerido no habeas corpus n. 313.021 ( $\mathrm{HC}$ n. 313.021). Perfilhando-se ao entendimento das $5^{\mathrm{a}}$ e $6^{\mathrm{a}}$ Turmas do STJ, entendeu o Ministro que não seria possível impetrar habeas corpus como substituto dos recursos ordinariamente previstos pela legislação processual penal, a não ser na hipótese em que o writ for meio idôneo para sanar flagrante ilegalidade perpetrada pelo tribunal a quo. Sendo assim, Falcão indeferiu o pedido liminar formulado no HC n. 313.021, por não vislumbrar na hipótese a flagrante ilegalidade passível de ser sanada pelo writ. $^{78}$

Nesse sentido, a defesa impetrou novo habeas corpus agora, perante o STF. Os autos foram distribuídos por sorteio à relatoria do Min. Teori Zavascki que, monocraticamente, deferiu o pedido liminar relativo à suspensão da ordem de prisão provisória ordenada antes do trânsito em julgado de sentença penal condenatória. A Procuradoria Geral da República manifestou-se favoravelmente à concessão da ordem. Contudo, o Pleno do STF denegou o habeas corpus e reverteu a liminar concedida pelo Min. Teori Zavascki.

Conforme aqui já salientado, o escopo deste trabalho é verificar a consistência teórica da mutação constitucional suscitada no voto do Min. Luís Roberto Barroso no HC n. 126.292 que, como dito, posicionou-se no sentido da possibilidade de cumprimento provisório de sentença penal

\footnotetext{
${ }^{78}$ Referido posicionamento não é isento de críticas. Abre-se um parêntese aqui para questionar ao STJ se a violação ao princípio da presunção de inocência não seria uma hipótese de "flagrante ilegalidade passível de ser sanada pelo writ". Se sim, o posicionamento adotado pelo Min. Francisco Falcão, ao apreciar o pedido liminar nos autos do HC n. 313.021, é contrário ao novo entendimento das $5^{\mathrm{a}}$ e $6^{\mathrm{a}}$ Turmas do STJ. Se não, questiona-se ao STJ o que de fato consistiria uma hipótese de "flagrante ilegalidade passível de ser sanada pelo writ", se nem uma clara e manifesta violação a um direito fundamental constitucionalmente previsto pode ser considerada enquanto tal. Ressalte-se que, atualmente, "a presunção de inocência aparece em inúmeras normas de Direito Internacional e, pode-se dizer, integraria o acervo hoje produzido pelo Constitucionalismo em geral” (MEYER, 2016, p. 01-02).
}

177 NETO, Almir Megali. A relativização do princípio da presunção de inocência a partir da mutação constitucional no habeas corpus n. 126.292 
condenatória ainda não transitada em julgado. Em sendo assim, o próximo tópico será destinado à identificação do posicionamento adotado por Barroso em seu voto.

\section{O POSICIONAMENTO ADOTADO PELO MIN. LUÍS ROBERTO BARROSO E AS SUPOSTAS MUTAÇÕES CONSTITUCIONAIS DO ART. $5^{\circ}$, INCISO LVII, DA CRFB/88}

Na primeira parte de seu voto, o Min. Luís Roberto Barroso apresenta o delineamento da controvérsia tratada no $\mathrm{HC}$ n. 126.292 fazendo, ainda, um resgate da jurisprudência oscilante do STF sobre a matéria. Ao final, conclui pela ocorrência de duas mutações constitucionais do art. $5^{\circ}$, inciso LVII, da CRFB/88. A primeira teria ocorrido em 2009 quando, a partir do julgamento do habeas corpus n. 84.078 (HC n. 84.078), o STF passou a entender que o princípio da presunção de inocência impediria o cumprimento provisório de pena determinada por tribunal de segunda instância. A segunda, por sua vez, teria ocorrido em virtude dos impactos causados por referido entendimento na realidade social no período compreendido entre 2009 e 2016.

Para ele, o entendimento adotado pelo STF a partir de 2009, “em primeiro lugar, funcionou como um poderoso incentivo à infindável interposição de recursos protelatórios" (Min. Luís Roberto Barroso, voto no HC n. 126.292, p. 32) que movimentavam o Poder Judiciário com considerável dispêndio de tempo e de recursos financeiros sem que houvesse em contrapartida "real proveito para a efetivação da justiça ou para o respeito às garantias processuais penais dos réus" (Min. Luís Roberto Barroso, voto no HC n. 126.292, p. 33). Cita dados estatísticos que comprovariam o baixo número de recursos extraordinários providos em favor do réu. ${ }^{7980}$

Em segundo lugar, referido entendimento teria favorecido apenas aos mais ricos que teriam "condições de contratar os melhores advogados para defendê-los em sucessivos recursos" (Min. Luís Roberto Barroso, voto no HC n. 126.292, p. 33), enquanto a parcela menos favorecida da população não conseguiria "bancar a procrastinação" pela falta de recursos ou pela falta de estrutura das Defensorias Públicas.

\footnotetext{
${ }^{79}$ Segundo o Min. Luís Roberto Barroso, apenas 1,5\% dos recursos extraordinários interpostos perante o STF em matéria penal seria provido em favor do réu e que de 2009 a 2016 as decisões absolutórias de mérito proferidas pelo STF em recursos criminais não chegariam a 0,1\% do total de decisões. Em 02 de fevereiro de 2018, os ministros Luís Roberto Barroso (STF) e Rogerio Schietti (STJ) publicaram artigo no jornal Folha de São Paulo no qual apresentaram dados relativos à pesquisa realizada pela Coordenadoria de Gestão da Informação do STJ sobre a porcentagem das decisões condenatórias reformadas pelo STJ em favor dos réus em sede de recurso especial. Diante do baixo índice de condenações revertidas apontado pela pesquisa, concluíram os ministros que não haveria justificativa para aguardar o trânsito em julgado para início do cumprimento da pena. Para tanto, veja-se: Barroso e Cruz (2018).

${ }^{80}$ O mesmo raciocínio fora utilizado na Itália quando da elaboração do Código Rocco. Naquele período, “o raciocínio era o seguinte: como a maior parte dos imputados resultavam ser culpados ao final do processo, não há o que justifique a proteção e a presunção de inocência" (LOPES JÚNIOR, 2014, p. 935).
}

Revice-Revista de Ciências do Estado, Belo Horizonte | v.3, n.2.2018 | p.174-195 
Por fim, "o novo entendimento contribuiu significativamente para agravar o descrédito do sistema de justiça penal junto à sociedade" (Min. Luís Roberto Barroso, voto no HC n. 126.292, p. 34), pois a imprescindibilidade da observância do trânsito em julgado de recursos extraordinário e especial levaria, na maior parte dos casos, à prescrição da pretensão punitiva estatal e, inevitavelmente, ao distanciamento temporal entre o momento da prática do delito e da punição.

Partindo de tais considerações, Barroso afirmou que uma leitura mais extremada e conservadora do princípio da presunção de inocência não mais se justificaria. Nesses termos, deverse-ia conferir interpretação ao art. $5^{\circ}$, inciso LVII, da CRFB/88, que estivesse em consonância com os anseios sociais, sendo a mutação constitucional, o instrumental teórico apto a chancelar referida mudança.

Para Barroso, a mutação constitucional seria um "mecanismo informal que permite a transformação do sentido e do alcance de normas da Constituição, sem que se opere qualquer modificação do seu texto" (Min. Luís Roberto Barroso, voto no HC n. 126.292, p. 30), em virtude "de uma mudança na realidade fática ou de uma nova percepção do Direito, uma releitura do que deve ser considerado ético ou justo" (Min. Luís Roberto Barroso, voto no HC n. 126.292, p. 30) para uma determinada sociedade em dado contexto histórico.

\section{A MUTAÇÃO (IN)CONSTITUCIONAL DO ART. 5 , INCISO LVII, DA CRFB/88}

\section{A COMPREENSÃO DOUTRINÁRIA DE LUÍS ROBERTO BARROSO SOBRE A MUTAÇÃO CONSTITUCIONAL}

Para o Min. Luís Roberto Barroso, a mutação constitucional seria decorrência lógica da interação existente entre normas constitucionais e realidade social, razão pela qual o Direito seria fortemente influenciado pela realidade social sob a qual opera. É nítido que Barroso pretende estabelecer um diálogo com sua produção doutrinária. ${ }^{81}$ Por isso, abre-se espaço aqui para expor a compreensão doutrinária de Barroso sobre a mutação constitucional para, ao final, contrastá-la com o posicionamento por ele adotado no caso em exame.

Pois bem, tanto em seu voto no HC n. 126.292 quanto em seu trabalho doutrinário, o Ministro reconhece que Direito e realidade social encontram-se em uma interação recíproca. Para ele,

\footnotetext{
${ }^{81}$ Vale destacar que, em diversas passagens de seu voto, o Ministro pretende estabelecer um diálogo com sua obra Curso de Direito Constitucional Contemporâneo.

179 NETO, Almir Megali. A relativização do princípio da presunção de inocência a partir da mutação constitucional no habeas corpus n. 126.292
} 
o Direito não existe abstratamente, fora da realidade sobre a qual incide. Pelo contrário, em uma relação intensa e recíproca, em fricção que produz calor, mas nem sempre luz, o Direito influencia a realidade e sofre a influência desta. A norma tem a pretensão de conformar os fatos ao seu mandamento, mas não é imune às resistências que eles podem oferecer, nem aos fatores reais do poder. No caso das mutações constitucionais, é o conteúdo da norma que sofre o efeito da passagem do tempo e das alterações da realidade de fato (BARROSO, 2015, p. 161).

Nesses termos, para Barroso, seria preciso compatibilizar dois conceitos caros à teoria constitucional, a saber, o da rigidez constitucional e o da plasticidade das normas constitucionais. A rigidez constitucional "procura preservar a estabilidade da ordem constitucional e a segurança jurídica" (BARROSO, 2015, p. 162), enquanto a plasticidade "procura adaptá-la [Constituição] aos novos tempos e às novas demandas, sem que seja indispensável recorrer, a cada alteração da realidade, aos processos formais e dificultosos de reforma" (BARROSO, 2015, p. 162). Barroso não fornece maiores explicações sobre como seria possível compatibilizar a rigidez constitucional e a plasticidade das normas constitucionais com a mutação constitucional, nos termos em que por ele definida. ${ }^{82}$ De qualquer maneira, conclui que

além do poder constituinte originário e do poder constituinte de reforma constitucional existe uma terceira modalidade de poder constituinte: o que se exerce em caráter permanente, por mecanismos informais, não expressamente previstos na Constituição, mas indubitavelmente por ela admitidos, como são a interpretação de suas normas e o desenvolvimento de costumes constitucionais (BARROSO, 2015, p. 162).

Adiante, Barroso (2015, p. 162) afirma "que como intuitivo, a mutação constitucional tem limites, e se ultrapassá-los estará violando o poder constituinte, e em última análise a soberania popular". Os limites da mutação constitucional seriam:

a) as possibilidades semânticas do relato da norma, vale dizer, os sentidos possíveis do texto que está sendo interpretado ou afetado; e b) a preservação dos princípios fundamentais que dão identidade àquela específica Constituição. Se o sentido novo que se quer dar não couber no texto será necessária a convocação do poder constituinte reformador. E se não couber nos princípios fundamentais, será preciso tirar do estado de latência o poder constituinte originário (BARROSO, 2015, p. 163).

Ao final, conclui que mutações inconstitucionais, ou seja, aquelas que extrapolariam os limites semânticos do dispositivo constitucional e que violariam os princípios fundamentais de uma ordem constitucional poderão ocorrer. Em tal caso, para ele, estar-se-ia vivendo um quadro de anormalidade institucional.

As mutações constitucionais que contrariem a Constituição podem certamente ocorrer gerando mutações inconstitucionais. Em um cenário de normalidade institucional, deverão ser rejeitadas pelos Poderes competentes e pela sociedade. Se assim não ocorrer, cria-se uma situação anômala, em que o fato se sobrepõe ao Direito. A

${ }^{82}$ Como seria possível, por exemplo, compatibilizar as exigências de estabilidade da ordem jurídico-constitucional e da segurança jurídica com a possibilidade de reformas constitucionais sem um procedimento previamente estabelecido como a mutação constitucional?

Revice-Revista de Ciências do Estado, Belo Horizonte | v.3, n.2.2018 | p.174-195 
persistência de tal disfunção identificará a falta de normatividade da Constituição, uma usurpação de poder ou um quadro revolucionário (BARROSO, 2015, p. 163).

\section{AS SEMELHANÇAS DOUTRINÁRIAS ENTRE BARROSO E HESSE}

Tanto em seu voto como em seu trabalho doutrinário, o Min. Luís Roberto Barroso faz menção à obra de Konrad Hesse (1983), ${ }^{83}$ tratando-a como trabalho seminal sobre o tema das mutações constitucionais. A partir de então, já é possível antever, pelo menos em sede doutrinária, qual a concepção do Ministro sobre a mutação constitucional. É que no debate alemão, a mutação constitucional não recebe tratamento unívoco, sendo trabalhada por diversas perspectivas que exprimem bem o momento histórico vivenciado pelos autores que sobre ela se debruçaram. ${ }^{84}$

Com Hesse, não é diferente. Escrevendo no contexto pós Segunda Guerra Mundial, o autor deixa transparecer em sua obra o espírito que orientou os trabalhos de elaboração da Lei Fundamental de Bonn. Os trabalhos constituintes contaram "com uma clara preocupação com a proteção dos direitos fundamentais, e, com isso, houve a incorporação de normas com elevado teor axiológico, além de um flagrante agigantamento da jurisdição constitucional" (OLIVEIRA, apud PEDRON, 2012, p. 128). Inserido neste contexto, Hesse propugnará que a Constituição é dotada de supremacia em relação às demais normas do ordenamento jurídico, razão pela qual toda legislação ordinária bem como o exercício do poder deveriam estar a ela submetidas.

A Constituição é a ordem jurídica fundamental da Comunidade. Ela fixa os princípios
diretores da relação aos quais deve-se produzir a unidade política e assumir as tarefas
do Estado. Contém os procedimentos para resolver os conflitos no seio da
Comunidade. Regula a organização e o procedimento de produção da unidade política
e de atuação estatal. Cria as bases e determina os princípios da ordem jurídica em seu
conjunto. Nisso tudo, a Constituição é o plano estrutural básico, orientado por
determinados princípios, que dão sentido à conformação jurídica de uma Comunidade
(HESSE, 2009, p. 86).

Assim como Barroso, Hesse reconhece que "a realidade social imprime pressões ao conteúdo da Constituição" (PEDRON, 2012, p. 131). Para Hesse, uma Constituição indiferente às mudanças sociais fatalmente perderia sua capacidade de conformação sobre esta mesma realidade, ou seja, perderia sua força normativa.

A constituição só pode cumprir suas tarefas onde consiga, sob mudadas circunstâncias, preservar sua força normativa, isto é, onde consiga garantir sua continuidade sem prejuízo das transformações históricas, o que pressupõe a conservação de identidade. Partindo disso, nem a constituição como um todo nem as suas normas concretas podem ser concebidas como letra morta, como algo estático e

83 Apesar de o Min. Luís Roberto Barroso se referir a Hesse a partir da obra Límites de la mutación constitucional de 1983, para fins deste artigo, será utilizada a obra Constituição e peculiaridade da constituição do mesmo autor publicado em língua portuguesa em 2009 pela Editora Saraiva.

${ }^{84}$ Para uma abordagem do debate alemão vejam-se Cattoni de Oliveira (2017) e Pedron (2012).

181 NETO, Almir Megali. A relativização do princípio da presunção de inocência a partir da mutação constitucional no habeas corpus n. 126.292 
rígido; precisamente sua continuidade pode chegar a depender da forma em que se encare a mudança (HESSE, 2009, p. 14).

Temendo o risco do descompasso entre texto constitucional e realidade social e, consequentemente, do esvaziamento da força normativa daquele, Hesse (2009, p. 14-15) assume a existência bem como a necessidade de mecanismos de atualização da Constituição. Seriam eles: a mutação constitucional e a reforma constitucional. A mutação constitucional seria o processo de alteração do conteúdo normativo de um determinado dispositivo constitucional sem que houvesse, contudo, alteração literal da Constituição (HESSE, 2009, p. 94; HESSE, 2009, p. 151-152).

Como ressalta Pedron (2012, p.131), "isso aconteceria nas normas que a Constituição deixa com conteúdos abertos, como, em regra, é o caso dos direitos fundamentais. Essas normas apresentam figura textual genérica dependendo das situações concretas de aplicação para adquirir concretude". Em sendo assim, destaca-se o papel da jurisdição constitucional na atribuição de sentido ao texto constitucional, na garantia de sua força normativa e da coesão social.

Para Hesse (2009, p. 08-09), a Constituição estabelece "uma relação de primazia e superioridade sobre todo o restante do direito interno, vinculando e submetendo todos os poderes públicos". Devido à sua supremacia, "e como elemento de garantia de tal vinculação, a própria Constituição construiu uma forma especial de jurisdição, a jurisdição constitucional, para policiar pela correta obediência às suas normas" (PEDRON, 2012, p. 131). Nesse sentido, o Tribunal Constitucional Federal Alemão "possui um importante papel de estabilização dos conflitos, fixando um procedimento que conduzirá a uma decisão pacificadora" (PEDRON, 2012, p. 131).

De acordo com Hesse, a preocupação do Tribunal deveria estar orientada por uma leitura material da Constituição de modo que seja possível conformar a realidade social aos seus ditames. O Tribunal seria "o principal agente produtor da mudança" (PEDRON, 2012, p. 132). Dessa maneira, a Constituição e

\footnotetext{
seus conteúdos são qualificados frequentemente como valores fundamentais, anteriores ao ordenamento jurídico positivo, valores que, pela recepção das tradições da democracia parlamentar liberal representativa do Estado de Direito liberal, do Estado Federal e pela incorporação de novos princípios, como, especialmente, o do Estado Social, resultaram unidos por obra das decisões do constituinte em uma "ordem de valores", constituindo um ente estatal que, embora ideologicamente neutro, não é neutro diante desses valores (HESSE, 2009, p. 75-76).
}

Logo, pode-se dizer que "Hesse insere-se na tradição da chamada Jurisprudência de Valores, para a qual a Constituição nada mais é do que uma ordem concreta de valores” (PEDRON, 2012, p. 132). A mutação constitucional seria relevante, pois "a manutenção dessa ordem axiológica implica na necessidade de atualização constante da própria Constituição" (HESSE, 2009, p. 77). Como “a afinidade máxima dessa ordem de valores é a promoção da 'integração estatal' [...] o jurista 
alemão compreende que tanto a mutação quanto a reforma são, portanto, ferramentas válidas e necessárias para a 'realização' da Constituição" (PEDRON, 2012, p. 132). Com isso, conservar-seia a força normativa da Constituição compreendida como sua capacidade de "operar na realidade da vida histórica de forma determinante e reguladora" (HESSE, 2009, p. 96).

Vale destacar que Hesse estabelece limites à mutação constitucional, pois "resulta inadmissível uma interpretação diferente dos enunciados constitucionais em franca contradição com o seu texto" (HESSE, 2009, p. 15). Nesses termos,

\begin{abstract}
ao qualificar a realidade inconstitucional como realidade constitucional, outorga-se força normatizadora a essa realidade, com o que, enquanto força normatizadora da "realidade", de antemão ela se sobrepõe à forma normatizadora do "Direito". A qualificação da realidade inconstitucional como realidade constitucional contém, portanto, uma opção - não raro, desde logo, inconsciente - contra a Constituição, privando-a de uma contemplação jurídico constitucional (HESSE, 2009, p. 99-100).
\end{abstract}

Assim, ao Tribunal Constitucional Federal Alemão, incumbiria a tarefa de atualizar o sentido normativo dos dispositivos constitucionais para satisfazer aos novos anseios sociais, respeitando os limites estabelecidos pela própria Constituição. Isso porque, nessa perspectiva, a Constituição refletiria a identidade de uma sociedade que supostamente compartilharia os mesmos valores. Justamente para garantia desta ordem de valores tida como compartilhada por toda sociedade é que Hesse defende a mutação constitucional como mecanismo apto a proteger a força normativa da Constituição.

Supostamente, essa carga de valores - como elementos metajurídicos e pré-jurídicos - funcionariam como condição de legitimidade da própria Constituição e de sua normatividade. [...]

Isto é, por meio da mutação constitucional, a própria elasticidade do texto e a abstração e indeterminação típica do conceito de princípios jurídicos - tomados com a carga axiológica - autoriza ao aplicador do direito - notadamente ao Tribunal Constitucional Alemão - a redefinição das normas referentes aos direitos fundamentais (PEDRON, 2012, p. 133).

O Min. Luís Roberto Barroso, pelo menos em sede doutrinária, parece comungar da mesma concepção de mutação constitucional de Hesse. Barroso também condiciona a alteração do sentido normativo de determinado dispositivo constitucional à alteração dos valores supostamente compartilhados pela sociedade. Assim como Hesse, Barroso também reconhece que deve haver limites à mutação constitucional, pois, conforme já indicado, ambos crêem na possibilidade de existirem mutações inconstitucionais. Ocorre que, não obstante as semelhanças doutrinárias entre Barroso e Hesse, o Ministro adotou em seu voto no HC n. 126.292 uma concepção distinta de mutação constitucional que remonta ao contexto autoritário em que o instituto fora gestado e que evidencia a inconsistência teórica de seu voto. 
O POTENCIAL AUTORITÁRIO DA MUTAÇÃO CONSTITUCIONAL: O VOTO DO MIN. LUÍS ROBERTO BARROSO E SUA SEMELHANÇA COM O PENSAMENTO DE GEORG JELLINEK, RUDOLF SEMND E HSÜ DAU-LIN

Não se está defendendo aqui que a eventual adoção da perspectiva de Hesse sobre a mutação constitucional tornaria os fundamentos trazidos pelo voto do Min. Luís Roberto Barroso nos autos do HC n. 126.292 em fundamentos constitucionalmente adequados. Isto conferiria apenas consistência teórica ao voto. Pelo contrário, o que se sustenta aqui é a insuficiência da mutação constitucional para lidar com a força normativa dos princípios e a desnaturação que seu uso faz do exercício da função jurisdicional.

Pois bem, para ser coerente com seu trabalho doutrinário, Barroso deveria demonstrar que, além de atender aos supostos anseios da sociedade, a mutação constitucional por ele suscitada obedeceria também aos limites semânticos do próprio art. $5^{\circ}$, inciso LVII, da CRFB/88 e ao atual projeto constituinte brasileiro. Contudo, o Ministro se furtou de fazê-lo. Talvez, porque a mutação constitucional por ele desenvolvida ferisse de morte o próprio teor do art. $5^{\circ}$, inciso LVII, da CRFB/88 e porque seja inconcebível a formação de juízo antecipado de culpa com a inauguração do projeto constituinte de 1988, preocupado em assegurar referida garantia (conquistada às duras penas) quando da transição para o regime democrático.

Dessa maneira, o que se constatou foi produção de uma mutação no intuito de manter a correspondência entre realidade social e a normatividade constitucional ao insuportável custo do próprio texto constitucional e dos princípios norteadores do atual projeto constituinte brasileiro. Daí ser possível sustentar a ocorrência de uma mutação inconstitucional do princípio da presunção de inocência.

Pois bem, o entendimento preconizado no voto do Min. Luís Roberto Barroso no HC n. 126.292 extrapolou os limites semânticos do art. 5º, inciso LVII, da CRFB/88, pois, por expressa dicção do respectivo dispositivo constitucional, somente será formado juízo de culpa após o trânsito em julgado de sentença penal condenatória. Antes do trânsito em julgado, admitem-se tão somente a decretação de prisões cautelares e em flagrante delito por meio de decisão judicial devidamente fundamentada proferida por autoridade judicial competente, conforme art. 93, inciso IX, da CRFB/88. Não havendo motivos para a decretação das prisões cautelares, a prisão se justificaria tão somente por antecipação do juízo de culpabilidade o que, por sua vez, é claramente vedado pelo texto constitucional. 
Além disso, o novo entendimento também não se justifica ante uma leitura principiológica da Constituição, pois não será objeto de deliberação nem pelo poder constituinte derivado reformador qualquer proposta de emenda à Constituição tendente a abolir os direitos e garantias fundamentais (art. 60, $\S 4^{\circ}$, inciso IV, da CRFB/88). Sendo a presunção de inocência um direito fundamental, o entendimento exposto por Barroso em seu voto possui claramente o potencial de restringir o exercício do referido direito, restando demonstrada, assim, a violação aos limites materiais de reforma da Constituição.

Incontestável, portanto, que o Min. Luís Roberto Barroso extrapolou os limites da mutação constitucional por ele mesmo construídos em sede doutrinária. Aliás, como já ressaltado, Barroso sequer faz menção a referidos limites em seu voto. Tudo isso faz com que a mutação constitucional por ele defendida se afaste da concepção de Hesse e se aproxime da compreensão de outros teóricos que se debruçaram sobre o estudo do referido instituto.

É o caso, por exemplo, de Georg Jellinek. Jellinek (1991, p. 07) compreende a mutação constitucional como "as mudanças que independem de alteração no texto constitucional, que são produzidas por fatos, mas sem a consciência de alteração". Reconhecendo a existência de omissão em algumas partes do texto constitucional, o autor afirma que “o Legislativo e o Judiciário precisam, no curso de suas atividades, desenvolver interpretações e definições a fim de ser possível atribuir algum sentido a determinadas passagens dos textos constitucionais" (JELLINEK, apud PEDRON, 2012, p. 94).

Para Jellinek, a mudança seria, portanto, fática sem qualquer intenção de alteração da Constituição. Haveria apenas uma alteração do sentido da norma sem que houvesse correspondente alteração do texto constitucional. Como visto, para referido autor, a mutação constitucional poderia ser realizada por decisões proferidas pela jurisdição constitucional.

Observando a tradição norte-americana, Jellinek (1991, p. 23) aponta que a decisão dos tribunais através, principalmente, do controle de constitucionalidade pode provocar uma mutação da Constituição, visto que eles assumem o papel de legisladores negativos e intérpretes da própria Constituição (PEDRON, 2012, p. 95).

Para Jellinek, o Direito seria parte "de um conjunto normativo maior, a ética social assume como pressuposta a solidariedade dos membros da comunidade, e propõe a cada membro, a assunção de um fim moral. Tal ética é histórica e cultural, e, por isso mesmo, cambiante" (PEDRON, 2012, p. 97). Dessa maneira, uma Constituição formal não poderia impedir o desenvolvimento de uma Constituição material tendo, portanto, de se ajustar aos novos valores agregados à sociedade e tidos como compartilhados por todos. Assim é que, para Jellinek, as modificações de sentido das 
normas constitucionais seriam devidas para adequar a Constituição formal a novas necessidades e realidades.

\begin{abstract}
Assim, as Constituições rígidas, como o caso da alemã imperial, não poderiam evitar que um direito constitucional não escrito se desenvolvesse, já que o substrato abstrato do direito, o mundo do Sollen, é dependente de uma conexão com a realidade, o mundo do Sein. Diferentemente, no caso de constituições flexíveis, haveria maior potencialidade de adaptação às necessidades e à realidade (VERDÚ, 1991, p. xiii).

Dessa forma, a figura que Jellinek chamará de mutação constitucional é, na realidade, confirmação dessa influência do real sobre o normativo; mas com isso há um preço a se pagar: a força normativa da constituição acaba por se curvar à força normativa do fato (PEDRON, 2012, p. 100).
\end{abstract}

Como bem ressalta Pedron (2012, p. 95), "Jellinek deixou de teorizar com maior profundidade os limites das mutações constitucionais”. Isso porque, conforme Lança (2014, p. 27), “a realidade histórica levou Jellinek (1991) a admitir que a mutação constitucional se processa à 'serviço' dos arranjos de poder, sem a possibilidade de contê-los juridicamente". Nesse sentido, a mutação dependeria apenas da constatação da necessidade de alteração do sentido do texto constitucional.

Assim como Jellinek, o Min. Luís Roberto Barroso reconheceu que a mutação constitucional seria produto da alteração da realidade social que precisaria tão somente ser reconhecida pelo Judiciário, em um processo não intencional, portanto. As alterações dos valores e das necessidades sociais foram os fundamentos que inspiraram a virada jurisprudencial operada por Barroso, aproximando-o novamente de Jellinek. Para ambos haveria, então, uma superioridade da realidade sobre a norma, já que a omissão de uma maior teorização em relação aos limites da mutação constitucional permitira qualquer alteração da Constituição.

Outro jurista que se debruçou sobre a mutação constitucional foi Rudolf Smend. Da produção doutrinária de referido autor também se aproximou Barroso em seu voto no $\mathrm{HC}$ n. 126.292. Pois bem, para Smend, seria preciso compreender o Estado como produto cultural e em permanente transformação.

As teorias do Estado e do Direito do Estado lidam com o Estado como parte da
realidade espiritual. Estruturas espirituais coletivas como parte da realidade espiritual.
Estruturas espirituais coletivas como parte da realidade não são substâncias estáticas,
mas unidades de sentido da vida espiritual real - atos espirituais. Sua realidade é de
atualização funcional, reprodução, ou mais precisamente, de contínua realização
espiritual e de formação (que pode ser progressiva ou degenerativa dependendo de
seu valor) - somente por força desse processo e por força de seu processo que elas
podem, ou poderão, renovar sua realidade de momento a momento (SMEND, apud
PEDRON, 2012, p. 113).

No constante processo de atualização espiritual do Estado, a partir das novas manifestações culturais da sociedade, seria preciso um processo de integração que se daria a partir de três modelos estruturais distintos: a integração pessoal, a integração funcional e a integração material. Nesses 
termos, pode-se dizer que a concepção de Smend sobre a Constituição se opõe tanto à concepção clássica segundo a qual uma Constituição consistiria em um documento escrito que organizaria o poder do Estado, a forma de seu exercício e garantiria aos indivíduos direitos em face do Estado, quanto à concepção lassalliana de que uma Constituição nada mais seria do que a soma dos fatores reais de poder de uma sociedade. ${ }^{85}$

\begin{abstract}
Assim, a Constituição deve ser um conceito em constante movimento. Isto é, a Constituição deve ser entendida em seu aspecto dúplice, quer como norma quer como realidade. Por isso mesmo, a Constituição deve desempenhar um papel fundamental ao ser uma ordem integradora: ela deve estimular e canalizar o processo de integração, mantendo-se aberta para oportunidades futuras de desenvolvimento e de normatização dos valores nacionais (KORIOTH, 2000. p. 210), e, dessa forma, é preciso assumir uma ideia de globalidade, na qual cada elemento se integra a um todo (SÁNCHEZ URRUTIA, 2000, p. 125) (PEDRON, 2012, p. 114).
\end{abstract}

Logo, Smend reconhece a incapacidade da Constituição regulamentar certas matérias. Isso exigiria do intérprete uma postura mais flexível, ou seja, capaz de orientar o processo de integração à luz dos valores compartilhados pela sociedade. Reconhecendo a importância dos direitos fundamentais para a cidadania e a democracia, não apenas como limites ao poder do Estado, mas, como a representação dos valores comuns de uma determinada coletividade, "Smend assumirá que a interpretação da constituição é uma atividade mais política que necessariamente jurídica, já que se volta para a perseguição de sua essência" (VERDÚ, apud PEDRON, 2012, p. 115).

Os direitos fundamentais, assim, representariam um sistema de valores concretos, que resumiriam o sentido da vida estatal na Constituição. Significam, ao mesmo tempo, uma vontade de integração material e a legitimação da ordem positiva jurídico-estatal: essa ordem jurídica seria válida enquanto representasse este sistema de valores formado pelos direitos fundamentais, convertendo-se, por isso, em legítima (BERCOVICI, 2004, p. 37).

Em seu voto no HC n. 126.292, Barroso afirma que a interpretação a ser conferida ao princípio da presunção da inocência deveria estar em sintonia com as demandas sociais por um sistema penal mais célere e eficaz. Além disso, o Ministro também afirmou que a leitura que se vinha dando ao art. $5^{\circ}$, inciso LVII, da CRFB/88, não seria mais condizente com os valores atualmente compartilhados pela sociedade, razão pela qual deveria ser restringido em prol da satisfação de outros interesses igualmente relevantes. Dessa maneira, é possível verificar que o sentido normativo dos direitos fundamentais variaria de acordo com os valores majoritariamente

85 Para Lassalle (1997, p. 92): "E aqui, pois, senhores, o que é, em essência a Constituição de um país: a soma dos fatores reais de poder que se regem nesse país. [...] Se capturados esses fatores reais de poder, se estendê-los em uma folha de papel, se lhes for dada expressão escrita, e a partir deste momento, incorporados em um papel, ai já não são simples fatores reais de poder, mas se há erigido em direito, em instituições jurídicas, e quem atenta contra eles atenta contra a lei, e é castigado".

187 NETO, Almir Megali. A relativização do princípio da presunção de inocência a partir da mutação constitucional no habeas corpus n. 126.292 
compartilhados pela sociedade. Ademais, assim como Smend, Barroso não faz maiores considerações em relação à existência de supostos limites à mutação constitucional. ${ }^{86}$

Costuma-se dizer que Hsü Dau-Lin foi o teórico que procurou sistematizar os estudos sobre a mutação constitucional procurando traçar uma verdadeira teoria do instituto (LANÇA, 2014; PEDRON, 2012). Apesar de ter sido discípulo de Smend e de, em virtude disso, ter sofrido a influência do pensamento de seu mestre, pode-se dizer que Dau-Lin dele pretendeu se afastar em questões relevantes de sua teoria.

Dau-Lin, assim como Smend, compreende que o sentido de uma Constituição somente será alcançado quando o texto constitucional se mostrar sensível às demandas políticas e sociais. Nesses termos, a mutação constitucional cumpriria a função integradora da Constituição bem aos moldes traçados por Smend.

Para Dau-Lin, o sentido global da constituição está em incorporar as necessidades políticas e as configurações sociais do Estado. Assim, seguindo a linha de Smend (1985), entende que as mutações constitucionais são decorrentes da própria função integradora da constituição jurídica, uma vez que esta refletiria as referidas necessidades e configurações estatais (LANÇA, 2014, p. 37).

Segundo Lança (2014, p. 37), Dau-Lin “identificava a mutação constitucional como um fenômeno exclusivo das constituições formais e rígidas, pois um Estado sem um documento formal, como é o caso britânico, gozaria, em sua opinião, de identidade entre realidade e normatividade”. Para Dau-Lin, a mutação constitucional seria produto de uma incongruência entre Direito e realidade a fim de manter a unidade estatal e garantir sua evolução em atendimento às suas necessidades vitais.

\begin{abstract}
A conjugação da ideia de mutação como decorrência da oposição entre direito e situação real com o entendimento de que, ao mesmo tempo, seriam instrumentos de manutenção da unidade do Estado, leva Dau-Lin a ser enfático em admitir a alteração do conteúdo das normas constitucionais, mesmo quando a essência modificada é contrária ao texto da norma. Isso se justificaria, pois, conforme reporta Dias (2012), para Dau-Lin, a constituição jurídica deveria ceder, não em razão da força da faticidade unicamente considerada, mas em virtude do atendimento das necessidades vitais do Estado. E a incorporação dessas necessidades, como dito acima, seria o sentido global da constituição (LANÇA, 2014, p. 38).
\end{abstract}

Como Dau-Lin considera que a Constituição capta seu sentido das necessidades políticas de uma determinada sociedade em um dado contexto histórico, ele admite a possibilidade de haver alterações no sentido normativo dos dispositivos constitucionais que sejam contrários à própria Constituição. Para referido autor, as modificações contrárias à Constituição não significam

${ }^{86}$ É preciso lembrar que "ao tratar do tema das mutações constitucionais, tem de se admitir que Smend (1985) não foi muito além de seus predecessores (Laband e Jellinek), quando o assunto é a elaboração de limites ao fenômeno, embora tenha superado a visão formalista de constituição" (LANÇA, 2014, p. 34).

Revice-Revista de Ciências do Estado, Belo Horizonte | v.3, n.2.2018 | p.174-195 
[...] quebra da Constituição, mas direito. É direito, ainda que seja divergente do texto constitucional e não possa ser compreendido por meio de conceitos e construções jurídicas formais. O seu funcionamento se encontra na singularidade valorativa do direito constitucional, na chamada, necessidade política, "como expressão da vitalidade inerente ao próprio desenvolvimento do Estado.” (DIAS, 2012, p. 54).

Disso, conclui-se "que Dau-Lin não hesita em admitir como fonte de mutações constitucionais legítimas a pressão das necessidades políticas e reais, mesmo que contrárias às normas plasmadas na constituição" (LANÇA, 2014, p. 39). Para ele, as necessidades vitais do Estado seriam superiores e imunes a qualquer constrangimento por parte do texto constitucional. Isso justificaria, para Dau-Lin, a ocorrência de mutações inconstitucionais. Diferentemente de seus predecessores, Dau-Lin se manifesta expressamente em relação a esta questão deixando

[...] um caminho aberto para que, por essa via, sejam introduzidas quaisquer alterações na Constituição - toda mudança na vida do Estado a justificaria - ainda quando afrontosa ao texto constitucional. Se toda necessidade política é direito, a teoria padece da ausência de imposição de limites ao conceito de mutação (DIAS, 2012, p. $56)$.

Dau-Lin identifica quatro tipos de mutações constitucionais, dentre elas, a realizada pelo Judiciário pela via da interpretação da Constituição (DAU-LIN, apud, PEDRON, 2012, p. 116-117). O jurista chinês afirma que esta modalidade de mutação constitucional se daria em virtude da alteração do sentido até então atribuído ao texto constitucional, mantendo-se intacta a expressão literal do dispositivo interpretado, extraindo-se dele norma diversa.

A partir de tais premissas, Dau-Lin (1998, p. 156; SÁNCHEZ URRUTIA, 2000, p. 130-131) desenvolverá a ideia de que a figura das mutações constitucionais não representa momentos de crise para a Teoria do Estado, ou mesmo para o Direito Constitucional; mas ao contrário ele assume a tese de que as mutações constitucionais são figuras que devem integrar o conceito de Constituição sob uma perspectiva dinâmica. Consequentemente, o autor irá criticar os autores presos à tradição do positivismo jurídico pela miopia diante da relação entre norma e realidade (PEDRON, 2012, p. 119).

Sendo assim, é possível traçar um paralelo entre a compreensão de Dau-Lin de mutação constitucional e do Min. Luís Roberto Barroso em seu voto no HC n. 126.292. Ora, ambos criticam aqueles que ficariam "presos às amarras do texto constitucional” ressaltando a necessidade do intérprete abrir os olhos às demandas da realidade sobre o texto da Constituição. Ambos assumem a mutação constitucional como instituto apto a intermediar as relações da Constituição com o tempo e com a realidade social sob a qual opera. Atualização esta que seria legitimada pelas demandas da sociedade e mesmo na hipótese de ser contrária à Constituição, ante a ausência de limites à mutação constitucional. 
Ante o exposto, constata-se a inconsistência teórica contida no voto do Min. Luís Roberto Barroso. De qualquer maneira, pretende-se demonstrar, na próxima seção, que, independentemente da perspectiva teórica sobre a mutação constitucional da qual se parta, referido instituto mostra-se insuficiente para lidar com a normatividade inerente aos princípios jurídicos e acaba por desvirtuar a jurisdição constitucional de suas funções.

\section{A INADEQUAÇÃO DA MUTAÇÃO CONSTITUCIONAL ANTE OS LIMITES DE ATUAÇÃO DA JURISDIÇÃO CONSTITUCIONAL}

Streck, Lima e Cattoni de Oliveira (2007, p. 53) apontam que "não se pode deixar de frisar, destarte, que a mutação constitucional apresenta um grave problema hermenêutico, no mínimo, assim como também de legitimidade da jurisdição constitucional”. Isso porque, para referidos autores, "a tese da mutação constitucional é compreendida mais uma vez como solução para um suposto hiato entre texto constitucional e a realidade social, a exigir uma jurisprudência corretiva" (STRECK; LIMA; CATTONI DE OLIVEIRA, 2007, p. 53).

A mutação constitucional compreendida como um processo informal de reforma da Constituição serviria, portanto, à atualização do sentido normativo desta, em vista de supostas imperfeições captadas por juízes sensíveis à satisfação ética de uma sociedade presumidamente homogênea. Nesse sentido, pode-se dizer que o socorro à mutação constitucional encobre, na realidade, um árduo paradoxo. É que sob o argumento de que a Constituição deva se adaptar às novas realidades sociais para manter e conservar sua legitimidade e normatividade acaba-se afirmando exatamente o oposto, isto é, a superioridade da realidade sobre a norma, principalmente quando não se estabelecem limites para o processo de reforma constitucional pela via da mutação.

A realidade social teria o potencial de constranger o sistema constitucional a ponto de reduzir as exigências deste à liberdade de conformação do intérprete. Sendo assim, quando a realidade social se apresentar de maneira contrária às disposições constitucionais, estaria o intérprete autorizado a desconsiderá-las. A uma, porque se não há limites à mutação constitucional, não há que se falar em mutações inconstitucionais, logo, todas as mutações seriam constitucionais. A duas, porque, seguindo este raciocínio, não teria sentido compatibilizar os "valores da rigidez constitucional e da plasticidade das normas constitucionais", apontados por Barroso (2015, p. 162) como caros à teoria constitucional, com a mutação constitucional, já que, admitir-se-ia o sacrifício da rigidez constitucional em prol da plasticidade de suas normas. Em tal perspectiva, a necessidade de atualização das normas constitucionais seria mais importante para a manutenção da Constituição do que a observância das exigências da rigidez constitucional. 
A ausência de limites à mutação constitucional, aliada à atribuição da competência para fazê-la à jurisdição constitucional, confere ao STF o papel de poder constituinte permanente, uma vez que o mesmo passa a estar autorizado a, por si próprio, estabelecer as bases sob as quais a Constituição será implantada sem qualquer limitação jurídico-normativa prévia podendo, portanto, agir livremente assim que bem lhe apetecer.

\begin{abstract}
Em síntese, a tese da mutação constitucional advoga em última análise uma concepção decisionista da jurisdição e contribui para a compreensão das cortes constitucionais como poderes constituintes permanentes. Ora, um tribunal não pode mudar a constituição; um tribunal não pode "inventar" o direito: este não é seu legítimo papel como poder jurisdicional, numa democracia (STRECK; LIMA; CATTONI DE OLIVEIRA, 2007, p. 54).
\end{abstract}

A função jurisdicional não se confunde de maneira alguma com a função legislativa e tampouco pode ser equiparada ao papel de titularidade do poder constituinte. Razão assiste a Streck, Lima e Cattoni de Oliveira quando afirmam que o papel da jurisdição constitucional é o de contribuir interpretativamente e com a participação da sociedade para a consolidação do sentido normativo e democrático expresso no projeto constituinte. Dessa maneira, "um tribunal não pode paradoxalmente subverter a constituição sob o argumento de a estar garantindo ou guardando" (STRECK; LIMA; CATTONI DE OLIVEIRA, 2007, p. 54).

No entanto, foi exatamente isso que se deu no $\mathrm{HC}$ n. 126.292, sendo a mutação constitucional um dos referenciais teóricos que chancelaram a violação do sentido normativo da Constituição. Como já demonstrado, não há fundamento legal e constitucional apto a legitimar o entendimento a que chegou o Min. Luís Roberto Barroso em seu voto, a não ser que se admita ser possível ao Judiciário declarar a inconstitucionalidade de dispositivos constitucionais originários ${ }^{87}$ e alterar a Constituição por um processo simples, informal e sem qualquer limitação.

$\mathrm{O}$ art. $5^{\circ}$, inciso LVII, da CRFB/88, é claro ao estabelecer que ninguém será considerado culpado antes do trânsito em julgado de sentença penal condenatória. Logo, a execução provisória de pena privativa de liberdade ordenada por autoridade judicial competente que não esteja fundamentada nos termos exigidos pela legislação processual penal para a decretação das prisões cautelares ou da prisão em flagrante delito vai de encontro à garantia constitucional supramencionada.

As prisões antecipada, preventiva e em flagrante delito, por excepcionarem a regra da vedação à prisão antes da formação do juízo definitivo de culpa, exigem a presença de seus requisitos autorizativos para que sejam decretadas. Sem a presença destes, não há que se falar em

${ }^{87}$ Segundo a jurisprudência do STF não há normas constitucionais originárias inconstitucionais. Sobre isso ver: BRASIL, Supremo Tribunal Federal, ADI 815, Rel. Min. Moreira Alves, julgamento 28/03/1996, DJ 10/05/1996. 191 NETO, Almir Megali. A relativização do princípio da presunção de inocência a partir da mutação constitucional no habeas corpus n. 126.292 
decretação de prisão por ausência de previsão legal nesse sentido, sob pena de violação à dogmática de proteção aos direitos fundamentais e aniquilamento da presunção de inocência.

Além disso, como visto, referido entendimento afronta os limites materiais ao poder constituinte derivado reformador, o que evidencia o potencial autoritário do manejo da mutação constitucional no HC n. 126.292 e o papel do STF enquanto titular do poder constituinte originário. Isso fica claro quando se tem em vista que, ao fundamento de estar elaborando norma nova supostamente mais condizente com as demandas da sociedade, o Min. Luís Roberto Barroso ter, na verdade, criado um novo texto, já que houve antecipação do momento a partir do qual se forma o juízo de culpa no direito brasileiro.

É preciso questionar com Streck, Lima e Cattoni de Oliveira (2007, p. 58) se “cabe ao STF 'corrigir' a Constituição? A resposta é não. Isso faria dele um poder constituinte permanente e ilegítimo. Afinal, quais seriam os critérios de correção, uma suposta 'ordem concreta de valores', um 'Direito Natural' no estilo de Radbruch?”. Adentrando na questão referente ao papel corretivo da jurisdição constitucional, questiona-se, novamente, com Streck, Lima e Cattoni de Oliveira (2007, p. 55) se a

interpretação da Constituição pode levar a que o STF produza (novos) textos, isto é, interpretações que, levadas ao limite, façam soçobrar os limites semânticos do texto no modo que ele vinha sendo entendido na (e pela) tradição (no sentido hermenêutico da palavra)?

A resposta para este questionamento também só pode ser negativa, pois do contrário estarse-ia admitindo a possibilidade de o Tribunal atuar para além dos limites estabelecidos na Constituição.

Além disso, o debate alemão no marco da crise do positivismo jurídico demonstra que a busca pela atualização da Constituição por meio da mutação constitucional é uma contradição em termos, uma vez que, na realidade, socorre ao positivismo do qual se pretendia emancipar sendo, ainda, depositária da concepção segundo a qual o sistema jurídico-normativo seria composto apenas por regras. A dificuldade da tradição positivista em lidar com o suposto hiato entre normatividade e realidade denuncia outro problema, qual seja, o de tratar adequadamente a relação entre Direito e política. E, por fim, demonstra a incapacidade de compreender o Direito para além de um conjunto de regras ao desconsiderar a força normativa dos princípios.

[...] a alegação de que é preciso adequar a norma a partir do texto normativo constitucional a uma realidade ainda é uma forma supervalorização do texto em detrimento da norma e também da realidade. Por meio da afirmação de que um tribunal irá proceder a uma mutação constitucional, tenta-se encobrir sua dificuldade em lidar com outro standard normativo, qual seja, a figura dos princípios jurídicos. 
Tal situação fica muito clara quando se volta aos momentos históricos nos quais a teoria da mutação constitucional foi pensada: a crise do positivismo na Alemanha. Nesse contexto, a solução realista - autorização de que o Judiciário crie uma norma substitutiva à Constituição - é, na verdade, outra fase do positivismo jurídico, e ainda um apego paradigmaticamente injustificado ao texto normativo constitucional (PEDRON, 2012, p. 210).

Dessa maneira, por meio da mutação constitucional, oferece-se uma solução empíricosociológica para um problema jurídico-normativo. Diante da percepção de um descompasso entre as demandas da sociedade e o texto constitucional, procura-se atualizar a interpretação da Constituição para que seja mantida a compatiblidade entre o devir social e o sentido atribuído às normas constitucionais por um processo mais simples e informal. Dessa maneira, ao lado da Constituição formal, desenvolver-se-ia "uma constituição material, para além ou mesmo contra a constituição formal” (CATTONI DE OLIVEIRA, 2017, p. 15). Daí a necessidade de superação do referido instrumental teórico.

\footnotetext{
Esse tratamento dado às mudanças constitucionais [pela mutação constitucional] nada mais seria, contudo, do que uma tentativa de explicação empírico-sociológica para um problema jurídico-normativo, carente, portanto, de mediação hermenêutica, ainda sendo pensado sobre o pano de fundo da própria tradição, em crise, do positivismo legalista $[\ldots]$ a análise histórico-social permanece externa à análise jurídica, tão somente, e quando muito, como sendo um olhar complementar, que, todavia, não contribui para uma visão que, da perspectiva interna da teoria do Direito, fosse não apenas capaz de superar o próprio dualismo metodológico, mas também o próprio positivismo, em crise, que lhe está subjacente (CATTONI DE OLIVEIRA, 2017, p. $15)$.
}

Percebe-se, assim, que o Min. Luís Roberto Barroso atuou no sentido de dar prevalência à realidade em detrimento da normatividade da Constituição, demonstrando que o socorro à mutação constitucional, no HC 126.292, funcionou como instrumento para supressão de direitos à margem da legalidade, de violação aos limites de atuação da função jurisdicional, além de ter consagrado o manejo inadequado dos princípios jurídicos.

\section{CONCLUSÃO}

Constata-se, assim, a existência de uma inconsistência teórica interna ao voto proferido por Barroso, na medida em que o Ministro se afastou das vertentes teóricas por ele suscitadas em seu próprio voto bem como a insuficiência da mutação constitucional para lidar com a relação entre Direito e política e com a força normativa dos princípios jurídicos. Ademais, o recurso à mutação constitucional importou em uma grave violação à ordem constitucional vigente, pois possibilitou a relativização do princípio da presunção de inocência evidenciando, assim, o risco a que se pode os direitos fundamentais quando o Judiciário atua no intuito de promover a satisfação de valores tidos 
como homogeneamente compartilhados pela sociedade a fim de promover a eficácia das normas constitucionais.

Diante disso, constata-se a necessidade de romper com a teoria tradicional da constituição para a qual a efetividade de uma determinada ordem constitucional estaria diretamente relacionada à correspondência ou à observância de suas prescrições normativas com os processos políticos e sociais. Em sentido diametralmente oposto a este e, com apoio nas Contribuições para uma Teoria Crítica da Constituição de Cattoni de Oliveira, propõe-se que legitimidade e efetividade constitucional não dependeriam da correspondência do conteúdo dos enunciados normativos abstratamente contidos no texto constitucional aos processos político-sociais observados na realidade, mas sim, da disputa interpretativa sobre o sentido de e da Constituição que possibilitaria o reconhecimento da normatividade constitucional em face do Direito e da política bem como o papel argumentativo de caráter hermenêutico-crítico dos participantes dos processos políticos.

\section{REFERENCIAS}

BARROSO, Luís Roberto. Curso de direito constitucional contemporâneo: os conceitos fundamentais e a construção do novo modelo. 5. Ed. São Paulo: Saraiva, 2015.

BARROSO, Luís Roberto. O novo direito constitucional brasileiro: contribuições para a construção teórica e prática da jurisdição constitucional no Brasil. Belo Horizonte: Fórum, 2018.

BARROSO, Luís Roberto; CRUZ, Rogerio Schietti. Execução penal, opinião e fatos, 2018. Disponível em: <https://www1.folha.uol.com.br/opiniao/2018/02/luis-roberto-barroso-e-rogerioschietti-execucao-penal-opiniao-e-fatos.shtml>. Acesso em: 02/02/2018.

BERCOVICI. Gilberto. Constituição e Estado de Exceção Permanente: a atualidade de Weimar. Rio de Janeiro: Azougue, 2004.

CATTONI DE OLIVEIRA, Marcelo Andrade. Contribuições para uma teoria crítica da constituição. Belo Horizonte: Arraes, 2017.

CATTONI DE OLIVEIRA, Marcelo Andrade; GOMES, David Francisco Lopes. História e tempo presente: $O$ debate constituinte brasileiro nas décadas de 1980-1990 e a atual proposta de uma nova assembleia constituinte. Revista Culturas Jurídicas, volume 3, número 6, p. 67-97, 2016.

DIAS, Cibele Fernandes. Decisões intermédias e mutação na justiça constitucional. Belo Horizonte: Arraes Editores, 2012.

HESSE, Konrad. Temas fundamentais de direito constitucional. São Paulo: Saraiva, 2009. 
HESSE, Konrad. Límites de la mutación constitucional. In: Escritos de Derecho Constitucional. Tradução de Pedro Cruz Villalón. Madrid: Centro de Estudios Consitucionales, 1983.

JELLINEK, George. Reforma y mutación de la Constituición. Tradução de Christian Förter. Madrid: Centro de Estudios Constitucionales, 1991.

LANÇA, João André Alves. Mutação constitucional: fundamentação e limites à luz da hermenêutica filosófica e da teoria estruturante do direito. 2014. Dissertação (Mestrado em Direito) - Faculdade de Direito da Universidade Federal de Minas Gerais, Belo Horizonte.

LASSALLE, Ferdinand. Qué es uma Constitución? 5ª ed. Barcelona: Editorial Ariel, 1997.

LOPES JÚNIOR, Aury. Direito processual penal. 11. ed. São Paulo: Saraiva, 2014.

MEYER, Emilio Peluso Neder. Presunção de inocência até a condenação em segunda instância? Jota, 2017. Disponível em: < http://jota.uol.com.br/presuncao-de-inocencia-ate-segunda-instancia >. Acesso em: 08/11/2017.

PEDRON, Flávio Quinaud. Mutação constitucional na crise do positivismo jurídico: história e crítica do conceito no marco da teoria do direito como integridade. Belo Horizonte: Arraes Editores, 2012.

\section{Tábua de decisões}

BRASIL, Superior Tribunal de Justiça, HC 313.021/SP, Decisão Monocrática Min. Francisco Falcão, julgamento 22/12/2014, DJ 02/02/2015.

BRASIL, Supremo Tribunal Federal, ADI 815, Rel. Min. Moreira Alves, julgamento 28/03/1996, DJ 10/05/1996.

BRASIL, Supremo Tribunal Federal, HC 84.078/MG, Rel. Min. Eros Grau, julgamento 05/02/2009, DJ 25/02/2010.

BRASIL, Supremo Tribunal Federal, HC 126.292/SP, Rel. Min. Marco Aurélio, julgamento 17/02/2016, DJ 16/05/2016. 